\title{
Effects of pulmonary and intercostal denervation on the response of breathing frequency to varying inspiratory flow
}

\author{
I. Mitrouska+, Z. Bshouty§, M. Younes§, D. Georgopoulos*
}

Effects of pulmonary and intercostal denervation on the response of breathing frequency to varying inspiratory flow. I. Mitrouska, Z. Bshouty, M. Younes, D. Georgopoulos. CERS Journals Ltd 1998.

ABSTRACT: In mechanically ventilated awake and sleeping humans, it has been shown that increasing inspiratory flow rate $\left(V^{\prime} I\right)$ exerted a reflex excitatory effect on respiratory output. Mechanoreceptors located in intercostal muscles or within the lung have been suggested as possible pathways that may mediate the excitatory effect of $V^{\prime}$. To test this, five patients with bilateral lung transplantation (LTP) and eight quadriplegics with spinal cord transection at the level of C6-C7 (QP) were studied.

Patients were connected to a volume cycle ventilator in the assist volume-control mode and $V^{\prime}$ I was randomly changed. $V^{\prime}$ I pattern was square and all breaths were patient-triggered. $V^{\prime}$ I values of 30,60 and $90 \mathrm{~L} \cdot \mathrm{min}^{-1}$ were studied. Each level of $V^{\prime}$ I was sustained for 15 breaths. Airway pressures, end-tidal partial pressure of carbon dioxide $\left(\mathrm{PCO}_{2}\right)$, airflows and volumes were measured breath by breath.

Thirty seven trials in LTP and sixty in QP, where $V^{\prime} I$ was randomly changed between 30 and $90 \mathrm{~L} \cdot \mathrm{min}^{-1}$, were analysed. In both groups of patients, minute ventilation increased and total breath duration decreased significantly as $V^{\prime} I$ increased. These changes were complete in the first breath after $V^{\prime}$ I transition, without evidence of adaptation of the response. The magnitude of the response did not differ between the two groups of patients and was comparable to that observed previously in conscious normal subjects.

We conclude that the excitatory effect of inspiratory flow rate on breathing frequency persists in patients who have pulmonary or intercostal denervation. These results do not favour receptors located within the lung (below the resection lines) or in the intercostal muscles to mediate the response of breathing frequency to flow rate. Eur Respir J 1998; 11: 895-900.
*Intensive Care Unit and +Pulmonary Department, University Hospital of Heraklion, University of Crete, Heraklion, Crete, Greece. \$Section of Respiratory Diseases, University of Manitoba, Winnipeg, Canada.

Correspondence: D. Georgopoulos University Hospital of Heraklion

Heraklion

Crete, 71110

P.O. Box 1352

Greece

Fax: 3081392413

Keywords: Lung transplantation mechanical ventilation quadriplegia

receptors

reflex

Received: July 281997

Accepted after revision January 161998

$\mathrm{ZB}$ is a Parker B. Francis Fellow in respiratory research.
In mechanically ventilated adult humans, it has recently been shown that inspiratory flow rates $\left(V^{\prime} \mathrm{I}\right)$ exert an excitatory effect on breathing frequency [1-4]. The response was complete within two breaths after a change in flow [1-4] and persisted, although to a lesser degree, during sleep [3], indicating a neural (reflex) mechanism mediated by an unknown pathway. The strength of this reflex was independent of breathing route, temperature and volume of inspired gas and upper and lower airway anaesthesia [2]. This effect appears to be independent of upper airway receptors, since it was observed in intubated patients in whom upper airways were bypassed [4].

The excitatory effect of $V^{\prime}$ I on breathing frequency has two important clinical implications for the management of mechanically ventilated patients on assisted modes. Firstly, an increase in flow rate intended to reduce inflation time and provide more time for expiration in order to reduce the dynamic hyperinflation (i.e. in patients with obstructive lung disease) [5] may be detrimental and elicit the opposite response (i.e. decrease in expiratory time) [4]. Secondly, an increase in $V$ 'I may lead to hyperventilation and respiratory alkalosis, important causes of various arrhythmia and weaning difficulty [6]. It follows that this flow-mediated reflex may influence decision-making regarding the ventilator settings and should be considered in the management of mechanically ventilated patients [7].

The receptors involved in mediating the excitatory effect of $V^{\prime}$ I are not known. It has been suggested that the response could be mediated through mechanoreceptors located in the chest wall or deep in airway mucosa [2, 3]. Indeed, studies in animals have shown a vagally mediated change in inspiratory activity in response to alteration in the rate of lung inflation [8]. Similarly, electrical stimulation of intercostal nerves in phase with inspiration results in tachypnoea [7], indicating the presence of receptors within the chest wall that are capable of mediating the breathing frequency response to inspiratory flow. Furthermore, it has been shown in humans, that afferent information from chest wall receptors may influence the breathing pattern and sense of dyspnoea [9].

Bilateral lung transplantation would be expected to interrupt the afferent vagal pathway for stretch receptors that are distributed in the airway smooth muscles within the lung. On the other hand, patients with complete spinal cord transection at the level of C6-C7 are devoid of afferent feedback from the rib cage (intercostal deafferentation). Thus, these two groups of patients may serve as a 
model to further elucidate the pathway through which the excitatory effect of $V^{\prime}$ I on breathing frequency is mediated. If pulmonary or intercostal afferents mediate the response to $V^{\prime}$ I then we would expect a different response from that observed in normal subjects. The purpose of the study, therefore, was to examine the response of breathing frequency to varying $V^{\prime}$ I in patients with bilateral lung transplantation and in quadriplegics with C6-C7 lesions.

\section{Methods}

Five patients with bilateral lung transplantation (LTP; three males, two females) and eight quadriplegics with spinal cord transection at the level of C6-C7 (QP; all male) were studied. All patients were unaware of the purpose of the study. They were studied while awake and sitting comfortably in a chair. The study was approved by the Hospital Ethics Committee and informed consent was obtained from each patient.

Pulmonary denervation was the result of bilateral LTP in three patients and heart-lung transplantation in two patients. All LTP patients had bibronchial anastomoses. Thus, in these patients the trachea retained its normal vagal innervation. Lung transplantation had been performed 10-36 months prior to the study. QP patients were studied 4-13 yrs after the injury. None of the patients had hypoxaemia (arterial oxygen tension $\left.\left(\mathrm{Pa}_{\mathrm{a}} \mathrm{O}_{2}\right)<9.1 \mathrm{kPa}\right)$ or hypercapnia (arterial carbon dioxide tension $\left(\mathrm{Pa}, \mathrm{CO}_{2}\right)$ $>5.85 \mathrm{kPa}$ ). In LTP, vital capacity (VC) and forced expiratory volume in one second (FEV1) were $88 \pm 2.2 \%$ and $85 \pm$ $3.5 \%$ of predicted, respectively. The corresponding values in QP were $65.0 \pm 1.8 \%$ pred and $62.3 \pm 2.4 \%$ pred.

The patients wore nose clips and breathed through a mouthpiece connected to a conventional volume-cycled mechanical ventilator (Bear 2; Bear Inter Med., Riverside, CA, USA), which delivered set tidal volume $(V \mathrm{~T})$ values at adjustable flow rates with a square-wave flow time profile. Airflow $\left(V^{\prime}\right)$ was measured using a heated pneumotachograph (Hans-Rudolph 3700; Kansas, USA) placed between the mouthpiece and the Y-shaped ventilator connector. The flow signal was electronically integrated to provide inspiratory and expiratory volume $(V)$. Airway pressure $(P$ aw $)$ was measured from a side port close to the mouthpiece (Micro-Switch, 140PC; Honeywell Ltd, Ontario, Canada). $\mathrm{CO}_{2}$ concentration was also monitored near the mouth using an infra-red sensor (Datex, Helsinki, Finland). The sample rate for each channel was $25 \mathrm{~Hz}$ (CODAS, DATAQ, Instruments Inc, OH, USA). All signals were stored on a computer disk for later analysis.

Initially, the patients breathed spontaneously through the ventilator. When ventilation and end-tidal partial pressure of carbon dioxide $\left(P \mathrm{ET}, \mathrm{CO}_{2}\right)$ were stabilized, $V^{\prime}, V$, $P$ aw and $P$ ET, $\mathrm{CO}_{2}$ were recorded for 2 min (spontaneous breathing). Then, the ventilator was set to assist-volume controlled mode $(\mathrm{A} / \mathrm{C})$, and $V \mathrm{~T}$ was adjusted for individual comfort. During the period of $V$ T adjustment, $V$ 'I was set at 50-60 L.min ${ }^{-1}$. The mandatory back-up rate was set at 0.5 breaths $\cdot \mathrm{min}^{-1}$, which meant that the patients had to trigger the ventilator for each breath and, thus, they were able to determine breathing frequency. Trigger sensitivity was set at maximum. At this setting the valves were triggered to open when $P$ aw was in the range of -1--2 $\mathrm{cmH}_{2} \mathrm{O}$. Depending on the rate of change in $P$ aw, there was a delay of 200-400 ms between the onset of inspiratory effort (defined as the time at which $P$ aw first became negative) and the ventilator triggering.

When the patients felt comfortable with the $V \mathrm{~T}$ delivered by the ventilator, $V^{\prime}$ I was changed randomly. $V^{\prime}$ I values of 30, 60 and $90 \mathrm{~L} \cdot \mathrm{min}^{-1}$ were examined. Each level of $V^{\prime}$ I lasted for 15 breaths. When the three levels of $V^{\prime}$ I were studied, the patient was disconnected from the ventilator and breathed spontaneously for $15 \mathrm{~min}$. Then, the patient was connected to the ventilator and breathed spontaneously for $5 \mathrm{~min}$. At the end of this period the ventilator was switched to $\mathrm{A} / \mathrm{C}$ mode, the $V \mathrm{~T}$ set to the comfortable level and flow trials with randomly changing $V^{\prime}$ I between 30 and $90 \mathrm{~L} \cdot \mathrm{min}^{-1}$ were repeated, as before. At least five such procedures, in which $V^{\prime}$ I was changed randomly between 30 and $90 \mathrm{~L} \cdot \mathrm{min}^{-1}$ were performed in each patient.

Breath-by-breath measurements of $V \mathrm{~T}, V^{\prime} \mathrm{I}$, mechanical inspiratory and expiratory time ( $t \mathrm{I}$ and $t \mathrm{E}$, respectively), total breath duration ( $t$ tot $)$, duty cycle $(t \mathrm{I} / t$ tot $), P$ ET, $\mathrm{CO}_{2}$ and $P$ aw were made. The value of $t$ tot was calculated from the $P$ aw tracing. The beginning of inspiration was deemed that point at which $P$ aw first became negative. The value of $t \mathrm{I}$ was measured as the interval from the beginning of inspiration to the onset of expiratory flow. On $\mathrm{A} / \mathrm{C}$ mode, $P$ ET, $\mathrm{CO}_{2}$ at each level of $V^{\prime}$ I was determined by averaging the last three breaths.

Data were analysed by paired t-test and analysis of variance (ANOVA), where appropriate. When the F-value was significant, paired t-test with Bonferonni correction for multiple comparisons was used to identify significant differences. A p-value of less than 0.05 was considered statistically significant. Values are expressed as mean \pm SEM.

\section{Results}

Ventilatory parameters during spontaneous breathing in LTP and QP are shown in table 1 .

On A/C mode, the comfortable $V$ T averaged $0.82 \pm 0.07$ $\mathrm{L}$ and $0.86 \pm 0.09 \mathrm{~L}$, in LTP and QP, respectively, significantly higher than the values observed during spontaneous breathing (paired t-test). This was true for all patients (LTP and QP).

Thirty seven trials in LTP and sixty in QP, where $V^{\prime} \mathrm{I}$ was randomly changed between 30 and $90 \mathrm{~L} \cdot \mathrm{min}^{-1}$ were analysed. In both groups we found no systematic changes in tot beyond the first two breaths after a change in flow rates (ANOVA). The results, therefore, are given as the average for all 15 breaths recorded within a given $V^{\prime} \mathrm{I}$.

Table 1. - Ventilatory parameters during spontaneous breathing

\begin{tabular}{lll}
\hline & \multicolumn{1}{c}{ LTP } & QP \\
\hline$V$ T L & $0.73 \pm 0.09$ & $0.66 \pm 0.04$ \\
$t$ tot s & $3.73 \pm 0.68$ & $4.17 \pm 0.45$ \\
$t \mathrm{I} / t$ tot s & $0.35 \pm 0.03$ & $0.38 \pm 0.02$ \\
$V^{\prime} \mathrm{E} \mathrm{L} \cdot \mathrm{min}^{-1}$ & $12.6 \pm 2.5$ & $10.2 \pm 1.0$ \\
$P \mathrm{ET}, \mathrm{CO}_{2} \mathrm{kPa}$ & $4.42 \pm 0.6$ & $4.56 \pm 0.2$ \\
\hline
\end{tabular}

Values are presented as mean \pm SEM. LTP: lung transplantation; QP: quadriplegics; $V$ T: tidal volume; tot: total breath duration; $t \mathrm{I} / t$ tot: duty cycle; $V$ E: minute ventilation; $P \mathrm{ET}, \mathrm{CO}_{2}$ : end-tidal partial pressure of carbon dioxide. 


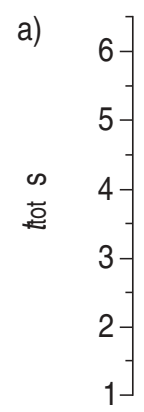
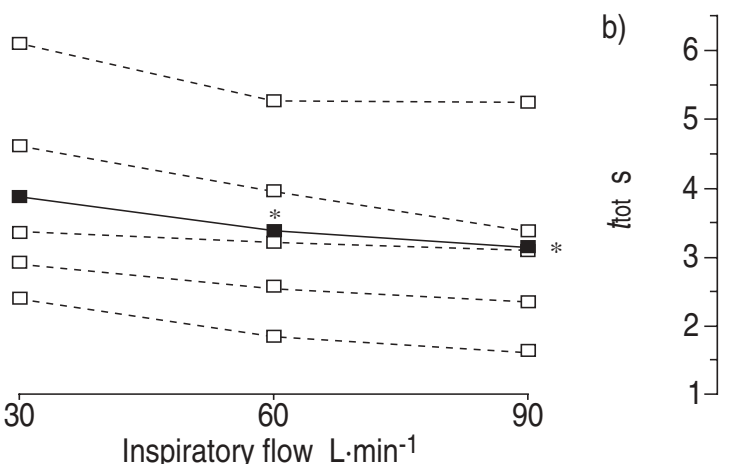

Fig. 1. - Total breath duration ( $t$ tot) as a function of constant inspiratory flow in patients with a) bilateral lung transplantation (LTP) and b) quadriplegics (QP). At each inspiratory flow, $t$ tot was the average value of 15 breaths. - $\square-$-: individual data; — - : mean data; *: significantly different than $t$ tot at an inspiratory flow of $30 \mathrm{~L} \cdot \mathrm{min}^{-1}$.

a)
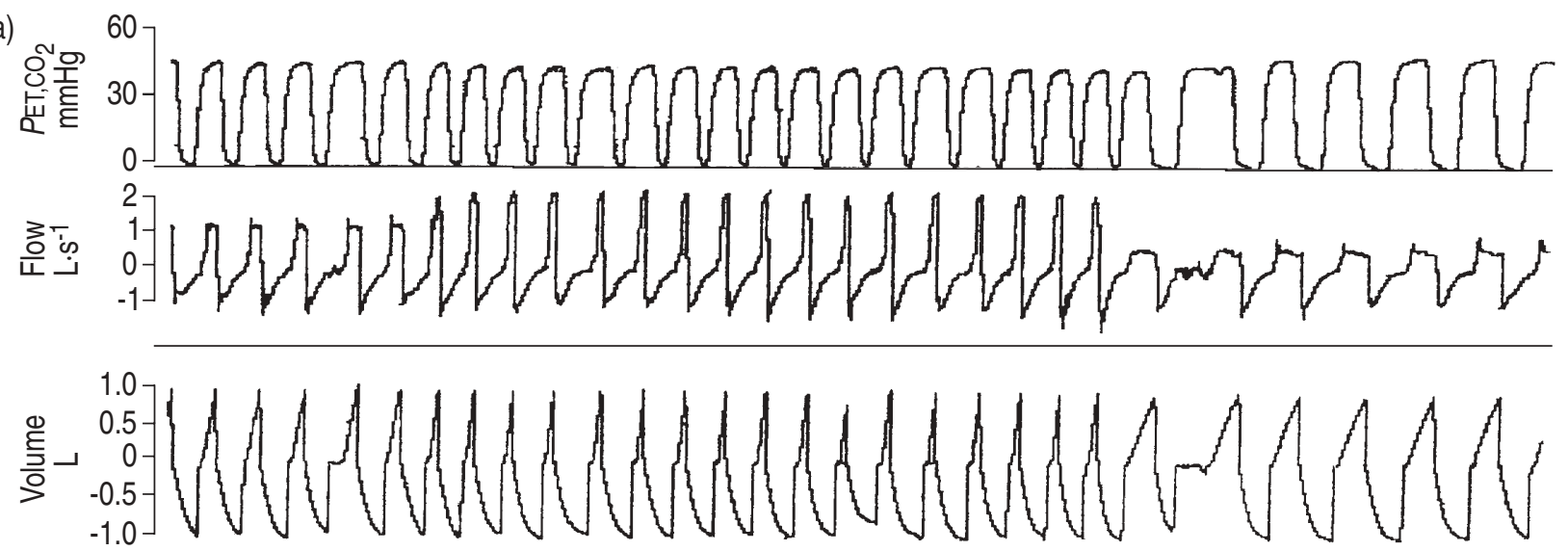

$\underset{60 \mathrm{~L} \cdot \mathrm{min}^{-1}}{\underbrace{3}_{0}}$
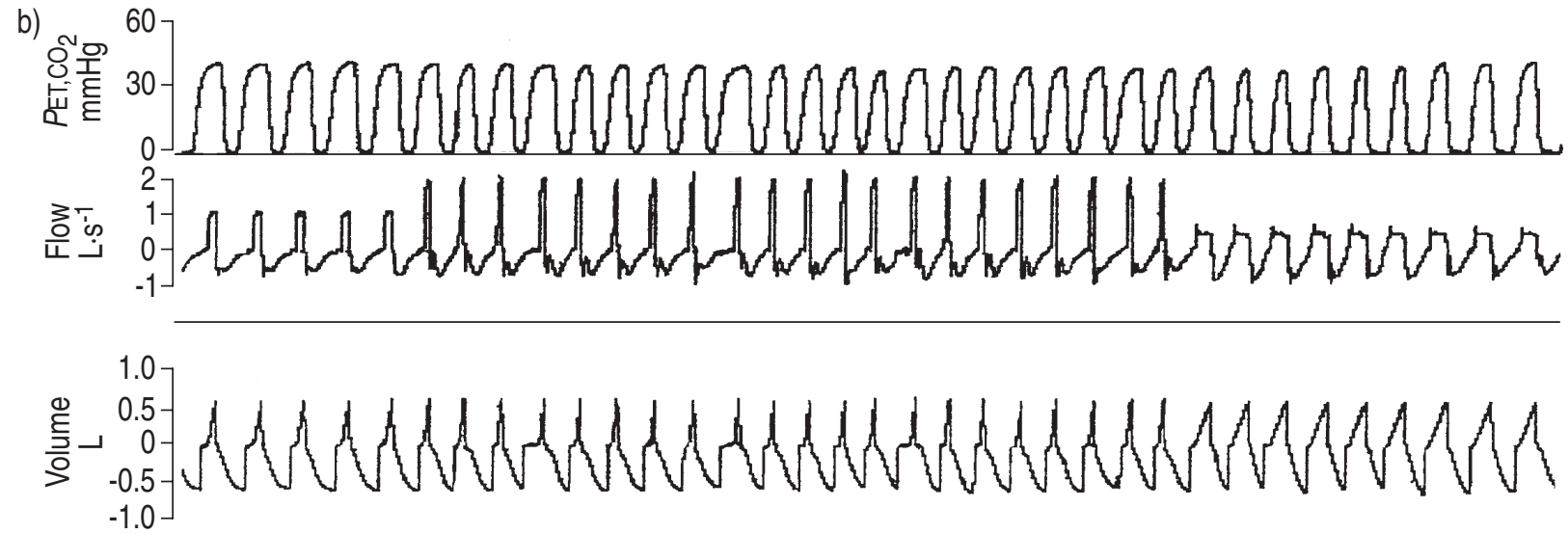

$\frac{\sqrt{60 \mathrm{~L} \cdot \mathrm{min}^{-1}} \frac{30 \mathrm{~L} \cdot \mathrm{min}^{-1}}{30 \mathrm{~L} \cdot \mathrm{min}^{-1}}}{2}$

Fig. 2. - Records of end-tidal partial pressure of carbon dioxide $\left(P E T, \mathrm{CO}_{2}\right)$, flow volume and airway pressure (Paw) in two representative patients, ventilated on assist control mode with different inspiratory flow rates. Inspiratory volume and flow are assigned positive values. a) patient with bilateral lung transplantation; b) patient with spinal cord transection at C6-C7. Inspiratory flow was changed from $60 \mathrm{~L} \cdot \mathrm{min}^{-1}$ to $90 \mathrm{~L} \cdot \mathrm{min}^{-1}$ to $30 \mathrm{~L} \cdot \mathrm{min}^{-1}$. Observe, in both patients, an increase in breathing frequency (decrease in total breath duration $(t$ tot $)$ ) at $90 \mathrm{~L} \cdot \mathrm{min}^{-1}$, which resulted in a progressive decrease in $P$ ET, $\mathrm{CO}_{2} .1 \mathrm{mmHg}=0.133 \mathrm{kPa}$. 
The effect of $V^{\prime}$ I on $t$ tot are shown in figure 1. Both in LTP and QP $V^{\prime}$ I had a significant effect on $t$ tot; $t$ tot decreased significantly in a graded manner as $V^{\prime} I$ increased (ANOVA; fig. 1). In all patients (LTP and QP) $t$ tot at $V^{\prime} \mathrm{I}$ of $90 \mathrm{~L} \cdot \mathrm{min}^{-1}$ was smaller than that at $30 \mathrm{~L} \cdot \mathrm{min}^{-1}$, the difference ranging 0.3-1.2 s and 0.5-1.9 s, respectively, in LTP and QP. Figures 2 and 3 show the response of breathing frequency to varying $V^{\prime}$ I in four representative patients (two LTP and two QP). The magnitude of the response did not differ significantly between LTP and QP (ANOVA). Because $V$ T was kept constant, minute ventilation ( $V$ 'E) followed the changes in breathing frequency. As a result $P$ ET, $\mathrm{CO}_{2}$, averaged over the last three breaths of each flow period, decreased with increasing $V^{\prime}$ I the decrease being significant in QP (table 2).

By study design, there was a significant decrease in $t \mathrm{I}$ with increasing $V^{\prime}$ I (table 3 ). On the other hand, $t \mathrm{E}$, which was partially controlled by the patients, showed a variable response. In some patients $t \mathrm{E}$ was actually decreased with increasing $V^{\prime}$ I, while in others there was a slight increase in $t \mathrm{E}$. This increase, however, was much smaller than expected. The expected increases of $t \mathrm{E}$ were based on an unchanged tot with increasing $V^{\prime}$ I and equated to the decline in $t \mathrm{I}(-\Delta t \mathrm{I})$. As a result of this variable response, the increase of $t$ E with increasing $V^{\prime}$ I was not significant (table $3)$.
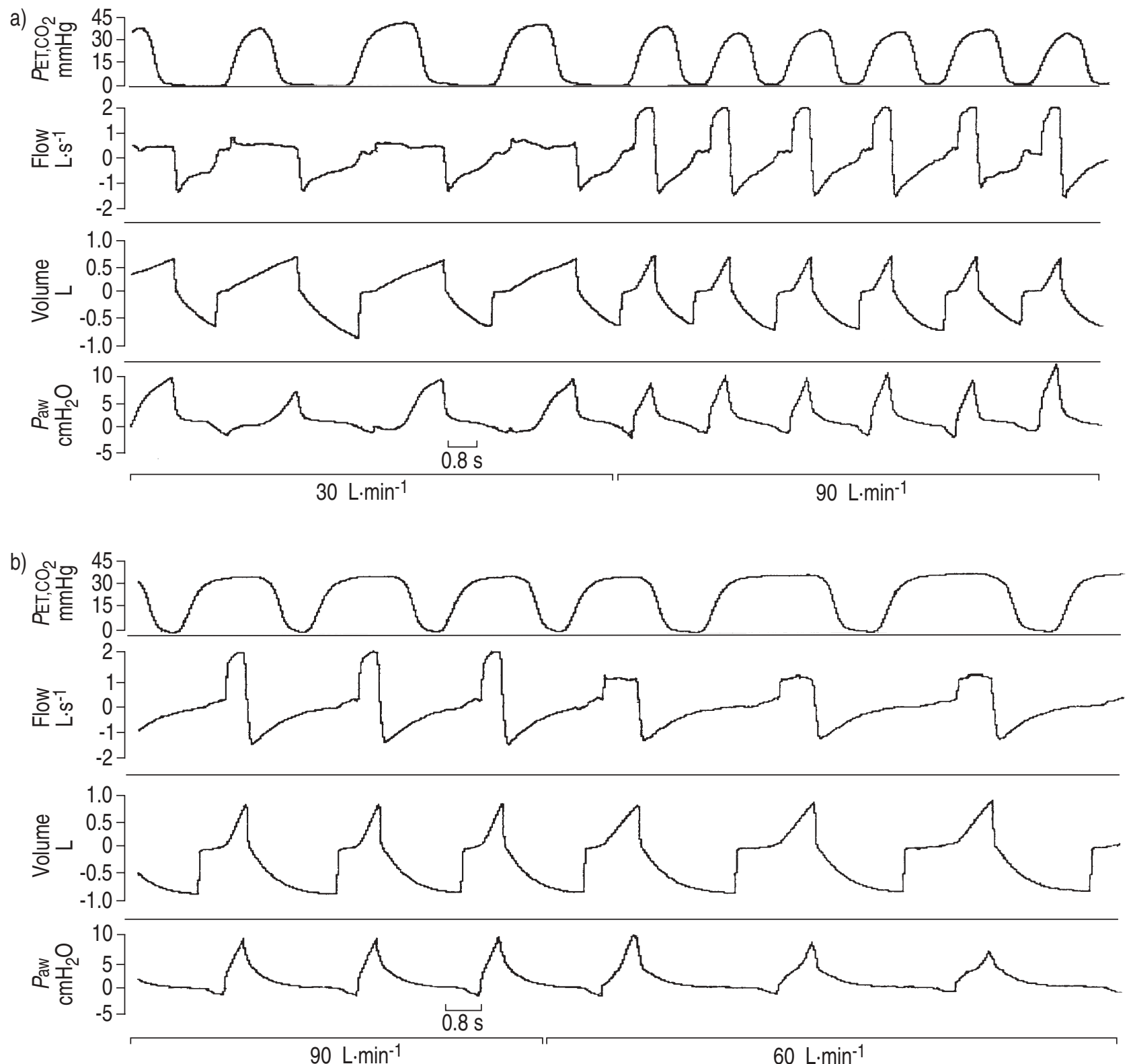

Fig. 3. - Records of end-tidal partial pressure of carbon dioxide $\left(P E T, \mathrm{CO}_{2}\right)$, flow, volume and airway pressure $(P$ aw) in two representative patients (different patients than in figure 2 ), ventilated on assist control mode with different inspiratory flow rates ( $V$ 'I). Inspiratory volume and flow are assigned positive values. For clarity of presentation the time scale has been expanded. a) patient with bilateral lung transplantation; b) patient with spinal cord transection at C6-C7. Observe that when $V^{\prime} \mathrm{I}$ was changed from 30 to $90 \mathrm{~L} \cdot \mathrm{min}^{-1}$ in the patient with bilateral lung transplantation (a) and from 90 to $60 \mathrm{~L} \cdot \mathrm{min}^{-1}$ in the patient with spinal cord transection (b) total breath duration (ttot) decreased and increased, respectively. The changes were evident in the first breath after $V$ 'I transition. Compared to the last breath of the previous $V^{\prime}$ I setting, $t$ tot of the first breath after $V^{\prime}$ I transition decreased from 2.7 to $1.8 \mathrm{~s}$ in figure $3 \mathrm{a}$ and increased from 2.6 to $3.8 \mathrm{~s}$ in figure $3 \mathrm{~b} .1 \mathrm{mmHg}=0.133 \mathrm{kPa}$. 
Table 2. - End-tidal partial pressure of carbon dioxide $\left(P \mathrm{ET}, \mathrm{CO}_{2}\right)$ at different levels of inspiratory flow $\left(V^{\prime} \mathrm{I}\right)$

\begin{tabular}{lcc}
\hline & \multicolumn{2}{c}{$P{\mathrm{ET}, \mathrm{CO}_{2}}_{2} \mathrm{kPa}$} \\
\cline { 2 - 3 }$V^{\prime} \mathrm{I} \mathrm{L} \cdot \mathrm{min}^{-1}$ & $\mathrm{LTP}$ & $\mathrm{QP}$ \\
\hline 30 & $4.18 \pm 0.6$ & $4.12 \pm 0.2$ \\
60 & $4.00 \pm 0.6$ & $3.89 \pm 0.2$ \\
90 & $3.92 \pm 0.6$ & $3.83 \pm 0.1$ \\
\hline
\end{tabular}

${\mathrm{PET}, \mathrm{CO}_{2}}_{2}$ was averaged over the last three breaths in each $V^{\prime} \mathrm{I}$ period. Values are presented as mean \pm SEM. For definitions of abbreviations see legend to table 1 .

The number of trials in which $V^{\prime}$ I was changed between 30 and $90 \mathrm{~L} \cdot \mathrm{min}^{-1}$ ranged 5-11 in the present patients. For a given $V^{\prime}$ I, the variability of $t$ tot within patients ranged $3.5-11.5 \%$ and $4.6-12.8 \%$ of mean $t$ tot, in LTP and QP, respectively, indicating good reproducibility of the response.

\section{Discussion}

The main finding of this study was that the excitatory effect of $V^{\prime}$ I on breathing frequency persisted in conscious patients with bilateral lung transplantation, as well as in quadriplegics with spinal cord injury at the level of C6-C7. The magnitude of the response did not differ between the two groups of patients and was comparable to that observed in previous experiments in conscious normal humans [1-3].

When conscious subjects or patients perform experiments such as these, it is possible that the results may be influenced by behavioural responses. This is unlikely to be the case in the present study. The patients were accusto-med to positive pressure by previous experiments and all breathed through the experimental setup on several occasions before the trial. The purpose of this was to familiarize them with the triggering mechanism of the ventilator and the resistance of the circuit. Attempts were made to minimize external stimuli that might result in behavioural stimulation of the breathing frequency, making it unlike- ly that this had a significant impact on the response we observed. In any event, this effect would probably be random and, thus, not have any appreciable influence on the multiple trials undertaken in each patient. This is supported by the minimal variability observed between trials. Furthermore, the changes in tot were completed within one or two breaths after flow transition (fig. 3 ) and re-mained relatively stable during the subsequent breaths, indicating that the response was mediated by a reflex mechanism. Because the patients perceived the changes in mechanical inspiratory time, "learned reaction" could be a possibility. However, the response was similar to that observed in normal subjects during non-rapid eye movement (NREM) sleep [3], where behavioural influence was not an issue. Also, all patients responded similarly to variation of $V^{\prime}$ I. Thus, "learned reaction" is unlikely to mediate the response. Finally, the patients were not aware of the purpose of the study and did not know what changes in ventilatory parameters were expected. All these reasons cast doubt that the patients voluntarily influenced the response we observed.

Both in LTP and in QP, tot decreased significantly in a graded manner with increasing $V^{\prime}$ I. Because $V$ T was kept constant, this resulted in hyperventilation and hypocapnia. The change in tot was evident in the first breath after flow transition and occurred despite different levels of $P$ ET, $\mathrm{CO}_{2}$, favouring a neural reflex mechanism. These results are quantitatively similar to those observed in conscious normal humans [1-2]. Indeed, we have shown in a previous study, during wakefulness and at comparable experimental conditions, that mean $t$ tot at $90 \mathrm{~L} \cdot \mathrm{min}^{-1}$ and $60 \mathrm{~L} \cdot \mathrm{min}^{-1}$ were $76 \%$ and $89 \%$ of that at $30 \mathrm{~L} \cdot \mathrm{min}^{-1}$, respectively (see fig. 1 of [2]). The corresponding values in the present study were $80 \%$ and $87 \%$, and $81 \%$ and $92 \%$, in LTP and QP, respectively. In addition, the response was qualitatively similar to that observed in normal humans during NREM sleep (see fig. 1 of [3]). The last observation confirmed that the excitatory effect of $V^{\prime}$ I on breathing frequency has a neural origin.

Breathing frequency remained relatively stable throughout the entire flow period, even though $P$ ET, $\mathrm{CO}_{2}$ was changing progressively (fig. 2). On A/C mode, at all $V^{\prime}$ I levels studied, $P$ ET, $\mathrm{CO}_{2}$ was lower than that during spontaneous breathing. This suggests that in awake states, during hypocapnia, breathing frequency is relatively insensitive to changes in the partial pressure of carbon dioxide $\left(\mathrm{PCO}_{2}\right)$. Indeed, it has recently been shown in conscious normal humans ventilated on pressure support or assist volumecontrolled modes, that breathing frequency is unaffected by $\mathrm{PCO}_{2}$ changes over a wide range of values $[10,11]$. It follows that, at least during hypocapnia, the reflex response of $t$ tot to varying $V$ I is not modulated by $P_{\mathrm{CO}_{2}}$.

Bilateral LTP interrupts the pulmonary branch of the vagus that provides the afferent route for stretch receptors within the lung. It is possible, however, that vagal afferent traffic is re-established after lung transplantation. Indeed, it has been shown that re-innervation of intrapulmonary stretch receptors occurs within 12 months following vagal section in dogs [13]. Furthermore, re-innervation of cardiac sympathetic afferent and efferent has been reported 1 yr after cardiac transplantation in humans [14]. Nevertheless, studies in patients with bilateral LTP showed absence of Hering-Breuer reflex 20-49 months after the surgery [15]. The Hering-Breuer reflex is thought to be the classic

Table 3. - Breathing pattern at different levels of inspiratory flow $\left(V^{\prime} I\right)$ in lung transplant (LTP) and quadriplegic (QP) patients

\begin{tabular}{|c|c|c|c|c|c|c|}
\hline \multirow{3}{*}{$V^{\prime} \mathrm{I} \quad \mathrm{L} \cdot \mathrm{min}^{-1}$} & \multicolumn{3}{|c|}{ LTP } & \multicolumn{3}{|c|}{ QP } \\
\hline & $t \mathrm{I}$ & $t \mathrm{E}$ & $t \mathrm{I} / t$ tot & $t \mathrm{I}$ & $t \mathrm{E}$ & $t \mathrm{I} /$ t tot \\
\hline & $\mathrm{s}$ & $\mathrm{s}$ & & $\mathrm{s}$ & $\mathrm{s}$ & \\
\hline 30 & $2.05 \pm 0.17$ & $1.83 \pm 0.62$ & $0.57 \pm 0.09$ & $2.16 \pm 0.22$ & $1.83 \pm 0.34$ & $0.56 \pm 0.06$ \\
\hline 60 & $0.91 \pm 0.07 *$ & $2.45 \pm 0.56$ & $0.30 \pm 0.05^{*}$ & $0.96 \pm 0.10 *$ & $2.72 \pm 0.29$ & $0.27 \pm 0.02 *$ \\
\hline 90 & $0.68 \pm 0.06^{* \dagger}$ & $2.44 \pm 0.60$ & $0.25 \pm 0.04 *$ & $0.72 \pm 0.07^{* \psi}$ & $2.47 \pm 0.28$ & $0.23 \pm 0.02 *$ \\
\hline
\end{tabular}

Values are presented as mean \pm SEM. $*: \mathrm{p}<0.05$ versus values at $30 \mathrm{~L} \cdot \mathrm{min}^{-1} ;{ }^{\dagger}: \mathrm{p}<0.05$ versus values at $60 \mathrm{~L} \cdot \mathrm{min}^{-1} ; t \mathrm{t}$ : inspiratory time; $t \mathrm{E}$ : expiratory time; $t \mathrm{I} / \mathrm{ttot}$ : duty cycle. For further definitions of abbreviations, see legend to table 1 . 
test of vagal afferent activity, and its absence indicates vagal interruption. Though we suspect that bilateral lung transplantation resulted in complete vagal interruption below the level of anastomosis, we cannot entirely exclude the possibility that partial re-innervation may occur.

It has been suggested that intercostal afferents may be the pathway through which the effects of inspiratory flow on respiratory output are mediated $[2,3]$. The chest wall contains a variety of afferents that respond to mechanical perturbation [16]. It has been shown that electrical stimulation of intercostal nerves in phase with inspiration shortens inspiratory time and total breath duration [7], indicating the presence of receptors within the chest wall that are capable of mediating the response to $V^{\prime}$ I. The results of the present study do not favour receptors located in rib-cage as mediating the reflex flow-effect on respiratory output. The excitatory effect of $V^{\prime} \mathrm{I}$ on breathing frequency persisted in patients devoid of afferent feedback from rib cage and the magnitude of the response was similar to that observed in normal humans [1-3].

In patients with bilateral LTP, stretch receptors above the resection line are intact. These receptors are, at least in animals, abundant [17-19]. Therefore, we cannot exclude the possibility that these stretch receptors mediate the excitatory effects of inspiratory flow rates on respiratory output. Similarly, we studied quadriplegics with lesions at the level of C6-C7. Spinal cord transections at these levels do not interrupt afferents from the diaphragm or other respiratory muscles that are innervated from higher levels. It is possible that these muscles may respond to mechanical perturbation and mediate the reflex response we observed.

Could the excitatory effect of inspiratory flow be mediated by laryngeal receptors, which were intact in both groups of patients? The design of our study did not permit exploration of this possibility. However, data in the literature indicate that laryngeal receptors are unlikely to mediate the response of breathing frequency to varying $V^{\prime} \mathrm{I}$; the response was preserved in intubated patients in whom the upper airway was bypassed [4].

In conclusion, the excitatory effect of inspiratory flow on breathing frequency was demonstrated in patients with bilateral lung transplantation, as well as in quadriplegics with spinal cord transection at the level of C6-C7. These results do not favour receptors located within the lung or in intercostal muscles as responsible for mediating the excitatory effect of inspiratory flow. However, receptors located above the resection line or in muscles innervated above C6 level (i.e. diaphragm) could be the pathways through which the effect of inspiratory flow on breathing frequency is mediated.

\section{References}

1. Puddy A, Younes M. Effect of inspiratory flow rate on respiratory motor output in normal subjects. Am Rev Respir Dis 1992; 146: 787-789.

2. Georgopoulos D, Mitrouska I, Bshouty Z, Webster K, Anthonisen NR, Younes M. Effects of breathing route, temperature and volume of inspired gas, and airway anes- thesia on the response of respiratory output to varying inspiratory flow. Am J Respir Crit Care Med 1996; 153: $168-175$

3. Georgopoulos D, Mitrouska I, Bshouty Z, Anthonisen NR, Younes M. Effects of nonREM sleep on the response of respiratory output to varying inspiratory flow. Am J Respir Crit Care Med 1996; 153: 1624-1630.

4. Corne S, Gillespie D, Roberts D, Younes M. Effect of inspiratory flow rate on respiratory rate in intubated ventilated patients. Am J Respir Crit Care Med 1997; 156: 304-308.

5. Georgopoulos D, Mitrouska L Markopoulou K, Patakas $\mathrm{D}$, Anthonisen NR. Effects of breathing patterns on mechanically ventilated patients with chronic obstructive pulmonary disease and dynamic hyperinflation. Intensive Care Med 1995; 21: 880-886.

6. Pierson DJ. Complications of mechanical ventilation. Curr Pulmonol 1990; 11: 19-46.

7. Pack A, DeLaney RG, Fishman AP. Augmentation of phrenic nerve activity by increased rate of lung inflation. J Appl Physiol 1981; 50: 149-161.

8. Remmers JE. Inhibition of inspiratory activity by intercostal muscle afferents. Respir Physiol 1970; 10: 358-383.

9. Sibua M, Yamada M, Kanamaru A, et al. Effect of chest wall vibration on dyspnea in patients with chronic respiratory disease. Am J Respir Crit Care Med 1994; 149: $1235-1240$.

10. Georgopoulos D, Roussos C. Control of breathing in mechanically ventilated patients. Eur Respir J 1996; 9: 2151-2160.

11. Georgopoulos D, Mitrouska I, Bshouty Z, Webster K, Patakas D, Younes M. Respiratory response to $\mathrm{CO}_{2}$ during pressure support in conscious humans. Am J Respir Crit Care Med 1997; 156: 146-154.

12. Patrick W, Webster K, Puddy A, Sanii R, Younes M. Respi-ratory response to $\mathrm{CO}_{2}$ in the hypocapnic range in awake humans. J Appl Physiol 1995; 76: 2058-2068.

13. Clifford PS, Bell LB, Hopp FA, Coon RL. Reinnervation of canine tracheal stretch receptors. J Appl Physiol 1987; 62: 1912-1916.

14. Wilson RF, Christensen VB, Olivari MT, Simon A, White $\mathrm{CW}$, Larson DD. Evidence for structural sympathetic reinnervation after orthotopic cardiac transplantation in humans. Circulation 1991; 83: 1210-1220.

15. Iber C, Simon P, Skatrud JB, Mahowald MW, Dempsey JA. The Breuer-Hering reflex in humans: effects of pulmonary denervation and hypocapnia. Am J Respir Crit Care Med 1995; 152: 217-224.

16. Shannon R. Reflexes from respiratory muscles and costovertebral joints. In: Cherniack NS, Widdicombe JG, eds. Handbook of Physiology. The Respiratory System, Vol. 2. American Physiological Society, Bethesda, MD, USA. 1986; pp. 431-438.

17. Miserocchi GJ, Mortola J, Sant'Ambrogio G. Localization of pulmonary stretch receptors in the airway of the dog. J Physiol (London) 1973; 235: 775-782.

18. Roumy M, Leitner LM. Localization of stretch and deflation receptors in the airways of the rabbit. $J$ Physiol (Paris) 1980; 76: 67-70.

19. Sant'Ambrogio G, Miserocchi G. Functional localization of pulmonary stretch receptors in the airways of the cat. Arch Fisiol 1973; 70: 3-9. 